\section{A preliminary study of sleep disorders and daytime behaviour problems in children with Down's syndrome}

\section{Rebecca Stores}

\author{
Research Assistant, Sarah Duffen Centre, \\ University of Portsmouth
}

\begin{abstract}
The recent occurrence and severity of a range of sleep disorders were determined in a group of children with Down's syndrome, and compared with those in a group of non-disabled children with the same mean age and similar Social Economic Status distribution. Associations were explored between the sleep disorders in children with Down's syndrome and measures of their daytime behaviour. Frequently occurring sleep problems were found to be significantly more common in the group with Down's syndrome compared with the non-disabled group. The most common sleep problems showed a different pattern in the two groups. In the children with Down's syndrome, various significant associations were seen between the number of frequent sleep problems and specific types of disturbed daytime behaviour. Within the Down's syndrome group, boys had significantly more frequent sleep problems than girls. The findings show that sleep problems are common in children with Down's syndrome and that they are linked with disturbed behaviour during the day. The requirements for possible further research are discussed.
\end{abstract}

\begin{abstract}
Acknowledgements
The author would like to thank Dr Gregory Stores for his help and advice throughout the study, Sue Buckley for providing access to children on the Portsmouth Down's Syndrome Register, Dr Jenny Dennis for her encouragement and providing access to children on the Oxford Down's Syndrome Register, Miss Gillian Campling for allowing access to her findings on sleep problems in ordinary school children and Dr Paul Griffiths for his statistical advice.
\end{abstract}

(C) 1993, 1999. The Down Syndrome Educational Trust Down Syndrome Research and Practice 1993, 1 (1) 29-33

\section{Introduction}

Most children have disturbances of their sleep at some stage. For example, it is common for children to talk in their sleep at times or have occasional nightmares. Bedtime fears and rituals are also common, as are settling difficulties and night waking with demands for parents' attention. Richman (1981) reported that about $20 \%$ of one to two year olds wake their parents five or more times a week, with regular waking declining to $3 \%$ by eight years of age. 10 to $15 \%$ of children age one to eight years are said to regularly refuse to go to bed, insist on their parents sleeping with them or to take a long time to go to bed (Jenkins, Owen, Bax \& Hart 1984). 15\% of children wet the bed during sleep at the age of 5 declining to about $1 \%$ at age 14 (Kales, Soldatos \& Kales 1987).

How ever common such disorders are in children as a whole, they seem to be even more common in children with a learning disability. As part of their studies of the problems of families caring for a child with a learning disability, Pahl and Quine (1984) discovered that of 200 children under 16 years of age living in Kent, $51 \%$ were said by their mothers to have difficulty in settling at night and $67 \%$ woke at least once or twice a week disturbing their parents. Settling difficulties in particular persisted throughout childhood. Sleep problems were still present in many cases on follow up 4 years later (Quine and Pahl 1989).

Bartlett, Rooney \& Spedding (1985) collected information from the parents of 214 children with learning disabilities up to the age of 16 on the Southampton District Handicap Register and found that $80 \%$ had one or more sleep difficulties in the previous seven days; $56 \%$ had 1 to 4 difficulties and $23 \%$ had 5 to 10 difficulties. The findings again suggested that children with a learning disability were slower at growing out of sleep difficulties than can be expected in normal children.

Clements, Wing and Dunn (1986) studied 155 children with severe learning disability under the age of 16 on the Camberwell Register in London and found that $34 \%$ were said by their parents to have some type of severe sleep problem.

The sleep problems of 120 children with Down's syndrome aged 5 to 10, were studied by Cunningham (1986). Compared with a general population sample reported by Richman, Stevenson \& Graham (1982), a significantly higher proportion of these children were found to have serious problems in settling (20\%), waking at night (41\%) and insisting on sleeping with their parents $(24 \%)$. These differences were seen right through the age range.

All these studies indicate that children with a learning disability are at high risk from sleep disorders which often persist. The findings also suggest that sleep problems are associated with disturbed behaviour in the daytime, and with family stress. This was particularly obvious in the reports by Quine and Pahl (1989) and Clements and his colleagues (1986). Quine and Pahl found that parents of children with sleep problems were significantly more likely to report that their child was difficult to manage, could not be left unsupervised and was difficult to keep occupied and safe. Clements et al. found night waking to have strong associations with self injurious behaviour. Limited hours of sleep were associated with attachment to routines in other areas of behavioural 
functioning. Both problems were associated with daytime behavioural difficulties such as tantrums and destructiveness.

The aims of the present study were to describe the recent occurrence and frequency of a range of sleep disorders in a group of school aged children with Down's syndrome and to compare these with a group of non-disabled children. Within the group with Down's syndrome, possible relationships between the sleep disorders and daytime behaviour were explored.

The study was intended to improve on previous investigations by assessing sleep disorders much more extensively in terms of type and severity, and by employing measures of sleep and behaviour which have been shown to be psychometrically acceptable and also specially appropriate for studies of children with a learning disability.

\section{Method}

\section{Subjects}

The children with Down's syndrome were drawn at random from registers kept in Portsmouth and Oxford. Questionnaires were sent to the parents of a total of 40 children. Thirty six $(90 \%)$ agreed to take part.

For comparison with the sleep disorder findings in these children with Down's syndrome, information obtained by means of the same sleep questionnaire was available on a group of non-disabled children attending mainstream schools in the Banbury area of Oxfordshire. These children formed part of an ongoing collection of normative data for a series of childhood sleep disorder studies at the Park Hospital in Oxford. The findings of the 50 children whose questionnaires were returned first, were available for comparison with those on the group with Down's syndrome.

\section{Instruments}

\section{Sleep Questionnaire}

The most comprehensive sleep questionnaire available at present was developed in the USA (Simonds and Parraga $1982,1984)$. It is concerned with a wide variety of sleep disorders and sleep related behaviours which are likely to be detected by parents. The overall categories of sleep disorders corresponds to those described in the International Classification of Sleep Disorders (Association of Sleep Disorders Centers, 1979), namely disorders of initiating and maintaining sleep (insomnias), disorders of excessive daytime sleepiness (hypersomnias), episodic disturbances of behaviour occurring in sleep or made worse by sleep (parasomnias), and disorders of the sleep wake cycle. Although the categories used in the more recent International Classification of Sleep Disorders (Diagnostic Classification Steering Committee, 1990) have been rearranged, the above four basic types of sleep disorder are still identifiable. Additional items in the Simonds and Parraga questionnaire concern sleep behaviours such as restlessness, snoring and insisting on sleeping with someone else.

Usually the questionnaire is completed by the child's mother and takes about 10 minutes. The range of sleep disorders and behaviours covered by the questionnaire is comprehensive, but not off-putting to parents. An attempt was made to use words readily understood by informants. Slight changes were made to the wording of some items, to make them more appropriate for use in the U.K. For each problem or behaviour, mothers are asked if the child exhibits it, and if so, how frequently the sleep disorder or behaviour has occurred during the previous six months by checking a five point frequency scale: daily, more than once a week but not daily, two to four times a month, about once a month, or less than once a month. However, in the analysis, the frequency of sleep problems was simplified to the following 3 categories, which were considered to be the most important clinically: Never, Infrequent problem (i.e. infrequent occurrence, covering 'less than once a month', 'about once a month' and '2-4 times a month' and lastlyFrequent Problem (i.e. frequent occurrence covering 'several times a week' and 'daily'.

\section{Measures of behaviour}

Few children's behaviour scales have been developed which do not make excessive demands due to their length and complexity, and have also been shown to be reliable and valid.

The questionnaire used in the present study is The Aberrant Behavior Checklist (ABC) (Aman, M.G., Singh,N. N., Stewart,A.W. \& Field,C.J. 1985a). This instrument has an advantage for this study because it was specially developed for assessing problem behaviour in people with a learning disability. It is also considered to have various psychometric advantages over other instruments and has been used extensively in behavioural studies of people with a learning disability (Aman 1991), including children (Rojahn and Helsel 1991, Freund and Reiss 1991).

\section{Results}

\section{Comparison of general characteristics of the Down's syndrome and non-disabled groups}

Of the 36 children with Down's syndrome, $22(61 \%)$ were boys compared with 21 (42\%) in the non-disabled group. Mean age of the group with Down's syndrome was 8.9years, ranging from 4.5 to 13 and mean age of the non-disabled group was 8.67 , range 5.5 to 11 . The difference between the mean ages of the Down's syndrome and non-disabled group was not significant. The two groups also showed similar social class groupings with the majority of families in social classes I and II (47.2\% of Down's syndrome group and $54 \%$ of non-disabled group).

\section{Comparison of numbers of sleep problems in Down's syndrome and non-disabled children}

Initially these two groups were compared for thetotal number of sleep problems reported, regardless of the frequency of the problems. The average for the group with Down's syndrome was 7.39 problems (range 1 to 21 ) and for the nondisabled group 6.32 problems (range 0 to 15). This difference is not significant (Mann Whitney $U=975, p>0.05$ ). However, when only frequent problems were counted, the average for the children with Down's syndrome was 5.38 (range 1 to 19) and for the non-disabled children 2.94 (range 0 to 11). This difference between the two groups is significant $(\mathrm{U}=525.5, \mathrm{p}=0.001)$ 


\section{Comparison of types of frequent sleep problems in the children with Down's syndrome and the non-disabled children}

Table 1 shows the occurrence of frequent sleep problems for the Down's syndrome children and the non-disabled children. For the children with Down's syndrome they are listed from the most to the least common downwards.

Table 1. Proportion of children with Down's syndrome and non-disabled children displaying frequent sleep problems

\begin{tabular}{|c|c|c|c|c|}
\hline & \multicolumn{2}{|c|}{$\begin{array}{l}\text { Children } \\
\text { with } \\
(n=36)\end{array}$} & \multicolumn{2}{|c|}{$\begin{array}{l}\text { Non- } \\
\text { disabled } \\
\text { children } \\
(n=50)\end{array}$} \\
\hline & $\mathrm{n}$ & $\%$ & $\mathrm{n}$ & $\%$ \\
\hline Restless sleep & 22 & 61 & 6 & 12 \\
\hline Rituals & 21 & 58 & 17 & 37 \\
\hline Reluctance to go to bed & 17 & 47 & 21 & 42 \\
\hline Snoring & 15 & 42 & 5 & 10 \\
\hline Afraid of dark & 14 & 39 & 9 & 18 \\
\hline Wakes more than twice a night & 12 & 33 & 3 & 6 \\
\hline Grinds teeth & 10 & 28 & 1 & 2 \\
\hline Wakes before 5 am & 9 & 25 & 0 & 0 \\
\hline Needs security object & 9 & 25 & 20 & 40 \\
\hline Bedwetting & 7 & 19 & 1 & 2 \\
\hline Doesn't sleep soundly & 7 & 19 & 0 & 0 \\
\hline Limb movements & 6 & 17 & 2 & 4 \\
\hline Wakes tired & 5 & 14 & 9 & 18 \\
\hline Overactive during day & 5 & 14 & 5 & 10 \\
\hline Talks in sleep & 4 & 11 & 2 & 4 \\
\hline Daytime naps & 4 & 11 & 0 & 0 \\
\hline Must sleep with someone else & 4 & 11 & 2 & 4 \\
\hline Wakes in bad mood & 3 & 8 & 10 & 20 \\
\hline Drowsy during the day & 3 & 8 & 0 & 0 \\
\hline Reluctant to go to bed(fears) & 2 & 6 & 0 & 0 \\
\hline Gagging/choking & 2 & 6 & 0 & 0 \\
\hline Stops breathing & 2 & 6 & 0 & 0 \\
\hline Episodes of weakness in day & 2 & 6 & 0 & 0 \\
\hline Fear of dying & 2 & 6 & 1 & 2 \\
\hline Walks in sleep & 1 & 3 & 0 & 0 \\
\hline Nightmares & 1 & 3 & 0 & 0 \\
\hline Night terrors, headbanging tongue & 0 & 0 & 0 & 0 \\
\hline
\end{tabular}

bitting, paralysis on waking up and

irrestible sleep in day

There are some similarities between the groups in the type and commonness of sleep difficulties: reluctance to go to bed is prominent with similar proportions of children showing this feature in both groups, and many children in both groups need to have security objects. In other ways, however, the two groups are very different. Restless sleep is particularly prominent in the group with Down's syndrome with a difference compared with the non-disabled children of $49 \%$. Other items with large differences in the same direction are snoring (difference of $32 \%$ ) waking more than twice a night $(27 \%)$, grinds teeth $(26 \%)$, wakes before 5 am $(25 \%)$, rituals $(21 \%)$ and afraid of the dark (21\% difference). The other differences between the groups are less convincing because of the small numbers involved. No obvious difference was seen between the two groups for the parents' estimate of how long their child usually slept at night : children with Down's syndrome averaged 9.6 hrs (range 3.512 hours); non-disabled children 10.37 hours (range 7-12 hours).

\section{Daytime behaviour difficulties in children with}

\section{Down's syndrome}

\section{Aberrant Behaviour Checklist}

The children with Down's syndrome showed a wide range of scores on each of the 5 subscales. The average subscales scores and ranges are shown in Table 2.

Table 2. Scores of children with Down's syndrome and average scores obtained by Marshburn and Aman (1992) on $A B C$ subscales

\begin{tabular}{|l|c|c|c|}
\hline & Average & $\begin{array}{c}\text { Range of } \\
\text { DS } \\
\text { scores }\end{array}$ & $\begin{array}{c}\text { Maximum } \\
\text { possible } \\
\text { score }\end{array}$ \\
\hline Irritability & $\mathbf{5 . 0 ( 7 . 5 1 )}$ & $\mathbf{0 - 2 4}$ & 45 \\
\hline Lethargy & $\mathbf{2 . 5 8 3 ( 4 . 7 0 )}$ & $0-15$ & 48 \\
\hline Stereotypies & $\mathbf{1 . 5 2 8 ( 2 . 1 )}$ & $0-17$ & 21 \\
\hline Hyperactivity & $\begin{array}{c}\mathbf{8 . 8 6 1} \\
(11.32)\end{array}$ & $0-31$ & 48 \\
\hline $\begin{array}{l}\text { Inappropriate } \\
\text { speech }\end{array}$ & $\mathbf{1 . 9 7 2 ( 1 . 3 7 )}$ & $0-11$ & 12 \\
\hline
\end{tabular}

The figures in brackets are average scores obtained by Marshburn and Aman (1992) from 277 children with severe and profound learning disabilities aged between 6 and 13 years attending special education classes in the United States. These have been included as it is useful to have some score against which to compare the group with Down's syndrome's scores. In four of the five subscales i.e. irritability, lethargy, stereotypies and hyperactivity the Down's syndrome scores are lower than those obtained by Marshburn and Aman. However, the Down's syndrome group score slightly higher on inappropriate speech. Within the Down's syndrome group, it is clear that large individual differences exist in all the subscale scores with some children scoring at the lowest point and others scoring very much higher.

\section{Associations between frequent sleep disorders and daytime behaviour in children with Down's syndrome}

Relationships were explored between the total number of frequent sleep problems, and the $A B C$ subscales scores.

\begin{tabular}{|c|c|c|}
\hline & $r^{2}$ & $p$ value \\
\hline ABC Irritability & 0.309 & $<0.001$ \\
\hline Lethargy & 0.047 & 0.102 \\
\hline Stereotypies & 0.140 & 0.012 \\
\hline Hyperactivity & 0.268 & $<0.001$ \\
\hline $\begin{array}{l}\text { Inappropriate } \\
\text { speech }\end{array}$ & 0.054 & 0.087 \\
\hline
\end{tabular}

Table 3. Spearman rank correlations between total number of frequent sleep problems and daytime behaviour scores in children with Down's syndrome 
The results from the $A B C$ show that there are strong but selective associations between frequent sleep problems and daytime behaviours. Frequently occurring sleep problems are associated with daytime irritability, hyperactivity and stereotypies. No convincing associations were found with daytime lethargy and inappropriate speech.

\section{6) Other associations with number of frequent sleep problems.}

Within the group with Down's syndrome, boys were found to have more sleep problems than girls $(U=75, p<0.01)$. This difference was not seen in the normal group $(U=285.5$, $\mathrm{p}>0.05)$. Age was not significantly related to sleep problems in either the group with Down's syndrome or the nondisabled group $(U=142.5$ and 332 respectively, $p>0.05)$.

\section{Discussion}

The main findings in this preliminary study were that:

1) Compared with a group of non-disabled children with the same mean age and a similar social economic status distribution, the children with Down's syndrome showed significantly more frequently occurring sleep problems.

2) Although the children with Down's syndrome and the nondisabled children have various frequent sleep problems in common, children with Down's syndrome were much more likely to be affected by restless sleep, snoring, being afraid of the dark, waking more than twice a night, teeth grinding, waking before $5 \mathrm{am}$.

3) The children with Down's syndrome show wide individual differences in sleep disturbance and daytime behaviours. As a group they show lower average scores of irritability, lethargy, stereotypies and hyperactivity than a group of children with mixed forms of developmental disabilities, but score slightly higher on inappropriate speech.

4) Boys with Down's syndrome have significantly more frequent sleep problems than girls with Down's syndrome.

5) Strong positive associations were found in the group with Down's syndrome between the number of frequent sleep problems and daytime irritability, overactivity, stereotypies.

This study was exploratory in nature and the findings raise various issues which warrant further investigation. Firstly, is the pattern of sleep problems and their associations with behaviour different in Down's syndrome compared with other forms of learning disability? Quine and Pahl (1989) report that $44 \%$ of children with Down's syndrome had sleep problems and $57 \%$ with non-specific learning disability had these problems.

Secondly, can different subgroups of children with Down's syndrome be defined regarding sleep and behaviour problems? It seems clear that the stereotyped idea of a child with Down's syndrome as placid and easy to manage is too simple and that such children can be very different from each other (Selikowitz 1990). Further study, including detailed investigations of sleep problems, could help define possible subgroups needing different types of help.

In addition, the question arises, what are the causes of the many frequent sleep problems in children with Down's syndrome? Quine and Pahl (1989) point out that in their study, children with sleep problems were significantly more likely to suffer from epilepsy (33\% of children with sleep problems had epilepsy compared with $13 \%$ of children without sleeping problems). In contrast, Cunningham (1986) felt that the home environment, including maternal stress and the way the child was handled, was particularly important in the sleep problems in his group with Down's syndrome.

In the present study information was collected on some factors that might have been relevant to the cause of the children's sleep problems. These factors were: family history of sleep problem (positive in 5 or $13.89 \%$ of the children with Down's syndrome and 9 or $18 \%$ of the non-disabled children), serious illness or physical disability (6 or $16.67 \%$ of children with Down's syndrome only one of whom had epilepsy, and 7 or $14 \%$ of non-disabled children), current drug treatments ( 7 or $19.44 \%$ of the group with Down's syndrome and 4 or $8 \%$ of the non-disabled group) and number of children sleeping in same room as the child $(0.33$ with range 0 to 2 on the group with Down's syndrome and 0.42 range 0 to 2 in the non-disabled group). None of these differences would explain the greater number of frequent sleep problems in the children with Down's syndrome compared to non-disabled children.

Other questions raised by the study include the exact meaning of some of the sleep disorder items especially those which seem to be characteristic of the group with Down's syndrome, in particular restless sleep and snoring. Restlessness can mean a number of things and it would be interesting to obtain the details of what happens during the night in these children (e.g. by video recordings). Loud snoring can be a sign of obstructive sleep apnoea in children, as can restless sleep (Stradling,J.R., Thomas,G., Warley,A.R.H., Williams,P. \& Freeland,A. 1990).

Lastly, do sleep disorders cause disturbed daytime behaviour or is it the other way round? Both are possible, at least in the case of some sleep problems and behaviours. For example, if sleep is disturbed so that the child is not refreshed by sleep his/her behaviour is likely to be difficult during the day. On the other hand sleep problems might be part of the child's generally disturbed behaviour. Ways of exploring these possibilities include studies in which the exact timing and sequence of the appearance of sleep disorder and behavioural disturbance was known. Another approach could be to try to treat the sleep disorder to see if the daytime behaviour also improved as would be predicted if sleeping difficulties were the cause of daytime problems.

As mentioned earlier sleep disorders seem to be a cause of much additional distress for the families of children with a learning disability. It is important therefore that further research is done to discover more about the origins and the nature of such sleep disorders and to find ways of treating them effectively. Progress has already been made on using behavioural treatments for some forms of sleep disorder in children with learning disabilities (Quine and Pahl 1992) and perhaps these need to be used more widely rather than drug treatment which is limited in value (Ferber 1986). In addition wider help is needed, especially for families in which the child's sleep and behaviour is badly disturbed, including advice and support. 


\section{Current Research Programme}

The author is presently undertaking an extensive programme of research addressing the issues brought out by this preliminary study. The first stage has been an extensive survey of sleep and behaviour problems in a large group of school aged children with Down's syndrome. Information has also been collected from a group of non-disabled brothers and sisters of the children with Down's syndrome, a group of ordinary children not related to the children with Down's syndrome and lastly, a group of children with learning disabilities but not Down's syndrome, for comparison.

The three comparison groups have been included to investigate (a) the effects of parental style on sleep and daytime behaviour difficulties, (b) the effects of a child with Down's syndrome on the sleep of his/her brothers and sisters and (c) the effects of specifically Down's syndrome on sleep and daytime behaviour problems as opposed to learning disability in general.

The results of this phase will be published in the next issue of the journal.

The second stage will focus on the problems of disordered breathing and obstructive sleep apnoea experienced by children with Down's syndrome. The author will be looking at the effects of such problems on the daytime functioning of children with obstructive sleep apnoea and will also be investigating any improvements in daytime functioning following treatment of the apnoea.

This research programme is being funded by the Portsmouth Down's Syndrome Trust.

\section{References}

Aman,M.G. (1991)Assessing psychopathologyand behavior problems in persons with mental retardation: A review of available instruments. Rockville MD: U.S. Department of Health and Human Services.

Aman,M.G. \& Singh,N.N. (1986) Aberrant Behavior Checklist Manual. New York, Slosson Educational Publications.

Aman,M.G., Singh,N.N., Stewart,A.W. \& Field,C.J. (1985a) The Aberrant Behavior Checklist: a behavior rating scale for the assessment of treatment effects. American Journal of Mental Deficiency 89, 485-491.

Association of Sleep Disorders Centers (1979) Diagnostic classification of sleep and arousal disorders. Sleep 2, 1137.

Bartlett,L.B., Rooney,V. \& Spedding,S. (1985) Nocturnal difficulties in a population of mentally handicapped children. British Journal of Mental Subnormality 31, 54-59.

Clements,J. Wing,L. \& Dunn,G. (1986) Sleep problems in handicapped children: a preliminary study. Journal of Child Psychology and Psychiatry 27, 399-407.

Cunningham,C. (1986) The Effects of Early Intervention on the Occurence and Nature of Behaviour Problems in Children with Down's Syndrome. Abstract Summary of Final Report. The Hester Adrian Research Centre, University of Manchester.

Diagnostic Classification Steering Committee (1990) International Classification of Sleep Disorders: Diagnostic and Coding Manual. Rochester, American Sleep Disorders As- sociation.

Ferber,R. (1986)Solve Your Child's Sleep Problems. Dorling Kindersley, London.

Freund,L.S. and Reiss,A .L. (1991) Rating Problem Behaviours in Outpatients With Mental Retardation: Use of the Aberrant Behavior Checklist. Research in Developmental Disabilities, 12, 435-451.

Jenkins,S., Owen,C., Bax, M. \& Hart, H.(1984) Continuities of common behaviour problems in preschool children.Journal of Child Psychology and Psychiatry 25, 75-89.

Kales,A., Soldatos,C.R., Kales,J.D. (1987) Sleep disorders: insomnia, sleepwalking, night terrors, nightmares and enuresis. Annals of Internal Medicine 106, 582-592.

Pahl,J. \& Quine,L. (1984) Families with Mentally Handicapped Children: A Study of Stress and of Service Response. Health Services Research Unit, University of Kent at Canterbury.

Quine,L. \& Pahl,J. (1989) Stress and Coping in Families Caring for a Child with Severe Mental Handicap: a Longitudinal Study. Institute of Social and Applied Psychology and Centre for Health Services Studies, University of Kent at Canterbury.

Quine,L. (1992) Helping Parents to manage Children's Sleep Disturbance An Intervention Trial using Health Professionals, In Gibbons J (1992) The Children Act 1989 and Family Support: Principles into Practice. London: HMSO, 101-141.

Registrar General (1960) Classification of Occupations. London, Her Majesty's Stationary Office.

Richman,N. (1981) A Community survey of the characteristics of one to two year olds with sleep disruptions. Journal of the American Academy of Child Psychiatry 20, 281-291.

Richman,N., Stevenson,J. \& Graham,P. (1982)Pre-school to school - A Behavioural Study. London, Academic Press. Rojahn,J. \& Helsel,W.J. (1991) The Aberrant Behaviour Checklist with Children and Adolescents with Dual Diagnosis. Journal of Autism and Developmental Disorders 21, 1, 17-28.

Selizowitz,M. (1990) Down Syndrome The Facts. Oxford, Oxford University Press.

Simonds,J.F. \& Parraga,H. (1982) Prevalence of sleep disorders and sleep behaviours in children and adolescents. Journal of the American Academy of Child Psychiatry 21, 383-388.

Simonds,J.F. \& Parraga,H. (1984) Sleep behaviors and disorders in children and adolescents at psychiatric clinics. Developmental and Behavioural Pediatrics 5, 6-10.

Stradling,J.R., Thomas,G., Warley,A.R.H., Williams,P. \& Freeland,A. (1990) Effects of adenotonsillectomy on nocturnal hypoxaemia, sleep disturbance, and symptoms in snoring children. Lancet 335, 249-253.

\section{Sources of help for parents}

There are sleep clinics in some areas. Doctors or health visitors should know about the existence of these in a particular area. The following are national organisations involved in helping parents:

Cry-sis Support Group, BM Cry-sis, London, WC1N 3XX Tel. 071-404-501;

Parentline, Rayfa House, 57 HartRoad, Thundesley, Essex, SS7 3PD Tel. 0268757007. 